\title{
Imagens escolares na literatura: algumas reflexões
}

\author{
School pictures in literature: some considerations
}

\author{
Nilo Carlos Pereira de Souza \\ André TeIXEIRA CordeIRO **
}

Resumo: Um olhar da literatura sobre a escola nos possibilita novos ângulos de observação. Nas últimas décadas muitas coisas mudaram de forma significativa no mundo, mas a escola parece ter mantido, com poucas exceções, noções que resultam no fastio do aluno e na ausência de questionamentos. Nesse estudo, buscaremos perceber tais noções através das impressões escolares contidas nas seguintes obras: Emília no País da Gramática, de Monteiro Lobato; Alice no país das maravilhas, de Lewis Caroll; Chove nos campos de Cachoeira, de Dalcídio Jurandir; Zeus ou a menina e os óculos, de Maria Lúcia Medeiros e A professora de desenho e outras histórias, de Marcelo Coelho. Palavras-chave: literatura, escola, representações.

\begin{abstract}
A literary look at the school enables us new angles of observation. In recent decades many things have changed significantly in the world, but the school seems to have maintained, with few exceptions, notions that result in the student boredom and lack of questioning. In this study, we will seek to realize such notions through the school prints contained in the following works: Emília no País da Gramática, by Monteiro Lobato; Alice no país das maravilhas, by Lewis Carroll; Chove nos campos de Cachoeira, by Dalcídio Jurandir; Zeus ou a menina e os óculos, by Maria Lucia Medeiros and $A$ professora de desenho e outras histórias, by Marcelo Coelho.
\end{abstract}

Keywords: literature, school, representations.

\footnotetext{
* Professor da Universidade Federal do Pará.

${ }^{* *}$ Professor da Universidade Federal do Tocantins.
} 
A literatura, como toda a arte, é uma confissão de que a vida não basta. Talhar a obra literária sobre as próprias formas do que não basta é ser impotente para substituir a vida (Fernando Pessoa)

o final da década de 1990, Magda Soares (1999) apontava para o uso da literatura pela escola. Para Soares, o processo de escolarização da literatura, em geral, se dá de dois modos: quando a escola se apropria da literatura para seus fins pedagógicos, ou quando a literatura volta-se para atender os objetivos da escola. Nos dois casos, a literatura é concebida fora do campo da estética, ela ganha um papel utilitário, uma ferramenta para alcançar muitos desígnios, menos o prazer da leitura:

À primeira perspectiva está subjacente o conceito de que há uma literatura que é destinada $a$, ou que interessa a criança, da qual a escola lança mão para incorporála às suas atividades de ensino e aprendizagem, às suas intenções educativas (...). [A] segunda perspectiva sob a qual podem ser analisadas as relações entre escolarização e qual podem ser analisadas as relações entre escolarização e literatura infantil: quando se pensa uma literatura infantil como uma literatura produzida para crianças e jovens, o que significa produzida para a clientela escolar, portanto, produzida para consumo na escola ou através da escola, a expressão escolarização da literatura infantil toma o sentido de literatização do escolar, isto é, de tornar literário o escolar (SOARES, 1999, p. 18).

Soares, em seu discurso, acaba enveredando pelo questionamento sobre o conceito de Literatura Infantil e Juvenil. Contudo, acreditamos que o mais importante nessa questão seja mesmo a relação entre literatura e escola. Não são raros os trabalhos que abordam a literatura dentro do âmbito educacional, atribuindo uma função pedagógica ao texto literário. Também se pode falar em volumosos trabalhos que abordam as práticas pedagógicas inspiradas em obras literárias. Mas como será que a literatura aborda tais práticas escolares? Em ou- 
tras palavras, como a literatura representa o espaço escolar? Alguns trabalhos já fizeram esse percurso. É o que, por exemplo, encontramos em: Dozol, 2008, 2009; Aguiar, 2009; Galvão, 1998; Mazzari, 1997, 2010; Rocha e Neto, 2012, entre outros.

Em seu artigo "A escola na literatura: do escárnio à gratidão", Marlene de Souza Dozol (2008) discute o valor atual do ensino a partir das obras de Raul Pompéia, O Ateneu, e de Cora Coralina, "Cântico Excelso", do livro Vintém de cobre. Dozol dá ênfase ao contraponto da visão sobre a escola nas duas obras, uma negativa e outra positiva, respectivamente. Em outro artigo, "Memórias Escolares: sem Ressentimentos", Dozol se pergunta: "Se a literatura aparece como fonte legítima para inspirar, por meio da mágoa, da caricatura e do escárnio, duras reflexões sobre o tempo de escola, seria ela também fonte de gratas e apaziguadas memórias relativamente a esse mesmo tempo?" (DOZOL, 2009, p. 226). Nesse último texto, a autora mantém o foco em uma representação literária positiva da escola a partir da obra Balão Cativo, de Pedro Nava. Segundo Dozol, o escritor mineiro recorda a infância e a passagem pela escola: "As primeiras memórias escolares de Nava são de 1911 e remetem a uma ambiência agradável da qual fazem parte as professoras" (DOZOL, 2009, p. 226). Em A Escola e a Letra, livro organizado por Flávio Aguiar e Og Doria, é possível vislumbrar um panorama das impressões de variados escritores brasileiros sobre a escola. São cinquenta ensaios que analisam alguns textos literários de autores, como Machado de Assis, Mário de Andrade e Luís Fernando Veríssimo. O cenário construído através de obras de importantes escritores nos fala sobre o processo de aprendizagem no país. Para Flávio Aguiar:

Seja por que prisma for, irônico, trágico, cômico ou lírico, a evocação da escola aparece na pena (hoje teclado ou tela) de um grande número de escritores como a renovação de um compromisso de origem dentro de um processo geral de mudança ou modernização, assolados que somos por tais esforços desde os tempos coloniais (AGUIAR, 2009, p. 11).

A experiência escolar passa a ser o ponto em comum presente na produção literária em diferentes momentos históricos. Alguns escritores acabam produzindo uma rica fonte para se pensarem as impressões infantis sobre a escola. 0 acesso às impressões literárias, além de reconstituir vivências, reconstrói cená- 
rios e descreve práticas, se torna referência para a reflexão em busca de compreender os aparelhos de aplicação educacional e os modelos de organização escolar - não a única, mas decerto uma referência pertinente.

A reflexão que propomos nesse estudo se estabelece dentro dessa inversão de foco, na qual a escola é percebida sob o ângulo do literário. A ideia central é compreender como algumas personagens infantis presentes nas obras de Monteiro Lobato, Lewis Caroll, Dalcídio Jurandir, Maria Lúcia Medeiros e Marcelo Coelho lidam com a educação escolar. Nosso estudo não busca fazer uma análise completa da produção dos autores citados. Propomo-nos fazer as leituras de alguns textos específicos: Emília no País da Gramática, Alice no país das maravilhas, Chove nos campos de Cachoeira, Zeus ou a menina e os óculos e A professora de desenho, respectivamente. Também não pretendemos conduzir para nenhum juízo de valor sobre a escola. Nossa leitura almeja especificamente às impressões escolares contidas nas obras.

Uma das primeiras lembranças que se tem das leituras juvenis remonta a um clássico da literatura infantil brasileira: Emília no País da Gramática, de Monteiro Lobato. O livro de Lobato começa com a angústia da personagem Pedrinho quando sua avó, Dona Benta, chama-o para ensinar Gramática - isto, em plenas férias escolares. Muita gente que leu o livro de Lobato deve ter concordado com a personagem, que argumentava: “-Maçada, vovó. Basta que eu tenha de lidar com essa caceteação lá na escola. As férias que venho passar aqui são só para brinquedo. Não, não e não..." (LOBATO, 2009, p. 14). As palavras de Pedrinho deixam claro uma concepção negativa de escola, em especial, com o ensino de língua materna. Obviamente a avó do menino persiste com a proposta:

- Mas, meu filho, se você apenas recordar com sua avó o que anda aprendendo na escola, isso valerá muito para você mesmo, quando as aulas se reabrirem. Um bocadinho só, vamos! Meia hora por dia. Sobram ainda vinte e três horas e meia para os famosos brinquedos (LOBATO, 2009, p. 14).

A fala de Dona Benta é mais um apelo que um argumento. E o menino acaba cedendo, mesmo fazendo "bico". Mas o interessante vem depois quando Pedrinho compara as aulas da avó com as que ele recebe nas escolas: "- Ah, assim, sim! - dizia ele. - Se meu professor ensinasse como a senhora, a tal gramática até virava brincadeira. Mas o homem obriga a gente a decorar uma porção de 
definições que ninguém entende. Ditongos, fonemas, gerúndios..." (LOBATO, 2009, p. 14-15). Transformar o ensino de gramática em brincadeira, ou melhor, em uma verdadeira aventura, é o que acontece no desdobramento da história quando entra em cena a personagem Emília. A boneca de pano convida toda a criançada do Sítio para viajar até o "País da Gramática"; a proposta fantástica é feita assim:

- Pedrinho - disse ela um dia depois de terminada a lição -, por que, em vez de estarmos aqui a ouvir falar de gramática, não havemos de ir passear no País da Gramática?

O menino ficou tonto com a proposta.

- Que lembrança, Emília! Esse país não existe, nem nunca existiu. Gramática é um livro.

- Existe, sim. O rinoceronte, que é um sabidão, contou-me que existe. Podemos ir todos, montados nele. Topa? (LOBATO, 2009, p. 15).

Decerto que há no texto de Lobato uma crítica direta à forma como se ensina Língua Portuguesa nas escolas, ou melhor, à concepção escolar de ensino de língua materna. A aventura proposta pela boneca Emília é logo aceita pelos membros do Sítio, pois se trata antes de uma experiência viva, na qual todas as coisas fazem sentido, inclusive a gramática. Se Lobato expressa através de sua obra certa animosidade pelo espaço escolar, isso não significa que ele não perceba a importância do ato de educar. Pelo contrário, há toda uma proposição formativa em suas narrativas. Na mesma obra, percebem-se no desenrolar da aventura as trocas de informações com conteúdo escolar. Um bom exemplo é a diferença entre fonema e grafema apresentada pelo rinoceronte sem o formalismo de uma aula expositiva:

Parece que andam voando por aqui milhões de vespas invisíveis.

- É que já entramos em terras do País da Gramática - explicou o rinoceronte. Estes zumbidos são os SONS ORAIS, que voam soltos no espaço.

- Não comece a falar difícil que nós ficamos na mesma - observou Emília. - Sons Orais, que pedantismo é esse?

- Som Oral quer dizer som produzido pela boca, A, E, I, O, U são Sons Orais, como dizem os senhores gramáticos. 
- Pois diga logo que são letras! - gritou Emília.

- Mas não são letras! - protestou o rinoceronte. - Quando você diz A ou O, você está produzindo um som, não está escrevendo uma letra. Letras são sinaizinhos que os homens usam para representar esses sons. Primeiro há os Sons Orais; depois é que aparecem as letras, para marcar esses Sons Orais. Entendeu? (LOBATO, 2009, p. 17).

Lobato apresenta nesse trecho um dos princípios básicos do ensino-aprendizagem: o aprendido faz parte do vivido e o primeiro não se dá sem o segundo. Talvez esse seja o princípio básico que, se seguido, mudaria toda a concepção do processo educacional nas escolas.

Anterior a Lobato, Lewis Carroll também expressava tal princípio em sua obra mais conhecida: Alice no país das maravilhas. O aspecto desconexo entre a prática escolar e a realidade das crianças aparece entre as reflexões de Alice, indicando que a aprendizagem escolar acontece geralmente sem sentido e desinteressante:

\begin{abstract}
"Eu adoraria saber quantas milhas eu caí até agora", ela dizia em voz alta. "Eu devo estar chegando em algum lugar perto do centro da terra. Deixe-me ver. Até aqui eu já desci umas 400 milhas, eu acho... (você vê, Alice aprendeu uma porção desse tipo de coisas na escola e pensou que seria muito boa a oportunidade de colocar para fora seu conhecimento; mesmo não havendo ninguém para ouvir). "Sim, acho que está correto, mas em que Latitude e Longitude estaríamos?” (Alice não tinha a mais leve idéia do que Latitude era, ou Longitude tão pouco, mas ela pensava que eram boas palavras para se dizer) (CAROLL, 2002, p. 7).
\end{abstract}

De fato, Alice não sabe o que significam as palavras "latitude" ou "longitude" porque foram passadas de forma descontextualizada. Na verdade, Alice decorou as palavras, assim como decorou que elas têm algo a ver com o espaço e por isso associou à distância percorrida em sua queda. A sutil crítica de Caroll quanto a esse "tipo de coisas" que a menina aprendeu na escola, se encontra no fato de que tais "coisas" só passam a fazer algum sentido no momento em que Alice vivencia uma experiência que as tornam necessárias. Contudo, a forma como Alice aprendeu fez com que as palavras permanecessem como signos esvaziados. 
Mais do que simples ensinamentos, Caroll insere em sua obra princípios fundamentais no processo de aprendizagem das crianças: interação e pragmatismo. Diferente do que lhe é ensinado na escola (sem que ela aprenda), Alice demonstra que retém informações importantes fora do espaço escolar. Ao encontrar uma garrafa com uma etiqueta escrito "Beba-me", a menina se previne:

"Não, eu vou olhar primeiro", disse ela, "e ver se está marcado veneno ou não"; Alice já lera muitas lindas histórias sobre crianças queimadas ou engolidas por feras selvagens e outras coisas desagradáveis, tudo porque não tinham lembrado das regras simples que seus amigos falavam para elas. Por exemplo: um atiçador de lareira pode queimá-lo se você segurar por muito tempo, ou, se você corta seu dedo muito fundo com uma faca, geralmente sangra; e ela nunca esquecera aquela: se você beber de uma garrafa que diz "veneno" é quase certo que isso irá prejudicá-lo, cedo ou tarde (CAROLL, 2002, p. 10-11).

O interessante é perceber que esse aprendizado de Alice não foi construído na escola. O que ela demonstra ter aprendido foi repassado através de "regras simples", por leituras feitas fora do contexto escolar. Caroll indica ao longo da narrativa que o conteúdo escolar tem pouco aproveitamento na vida do sujeito. Na verdade, o baixo aproveitamento se dá menos pela relevância do que pela forma como tais conteúdos são trabalhados. No fundo, Alice não retém muitos conteúdos escolares porque sua memória - assim como a da maioria das pessoas - descarta o que não tem necessidade prática, ou o que não provoca algum sentimento. No entanto, saber se é veneno aquilo que se bebe, passa a ser uma informação extremamente importante para se manter viva.O livro de Caroll foi publicado em meados da década de 1860 , momento em que a sociedade europeia passava por profundas mudanças e o capitalismo entrava em outro estágio: grande crescimento industrial e organização de uma classe operária reivindicando melhorias sociais. Todas essas transformações provocaram, consequentemente, agitações no campo filosófico e científico que permitiram uma maior compreensão do ser humano. Neste caso, Caroll já antecipava em sua narrativa nonsense uma percepção de um modelo de escola que foi transplantado para o Brasil e também captado por Lobato, que escreveu boa parte de sua obra infantil ao longo da década de 1930 - um momento conturbado no cenário nacional, que significou o final da chamada Velha República. Lobato, assim como Caroll, 
também reflete os descompassos de um sistema educacional ineficaz e pouco atraente para as crianças e jovens.

O desencontro entre as práticas escolares e os anseios das crianças e jovens dentro da escola também aparece em outra obra publicada, em 1940: Chove nos campos de Cachoeira, de Dalcídio Jurandir. O escritor marajoara nos apresenta a trajetória do menino Alfredo e, em meio às suas angústias existenciais, uma visão da escola é também configurada:

Que desânimo para Alfredo aquela escola do Proença. O seu Anglo-Brasileiro ia se desfazendo aos poucos, ou pelo menos, se esfumando. Já queria ficar ao menos em Belém, nalgum grupo escolar. Mas a escola de Proença com a Flor, D. Rosa, o recreio à tarde, o Baltô sempre apanhando séries e séries de dúzias de bolos, Euzébia jogando a cantiga pra D. Rosa, a quantidade de chamadas - Flor? Vem cá, Flor... E Flor vindo, com o seu andar tímido, a pureza dos olhos azuis, das mãos alvas, da boca e daqueles cabelos que deixavam um perfume e uma vaga claridade entre os alunos maliciosos e oprimidos. Tudo aquilo era justamente o anti-AngloBrasileiro. Tudo fazia para que Alfredo se encharcasse de sonho, de imaginações. A bolinha subia e caía na palma da mão. A realidade daquela viagem para a escola só estava nos cajus. Alfredo tinha era camaradagem pelos cajueiros. Eles ensinavam mais que o seu Proença. Eram os cajus e a água fria na cuia da casa da siá Águeda. la de propósito por lá para tomar água. Uma cuia cheia. Que água! Os potes eram velhos, com limo e, nos fundos do quintal, o poço. As filhas da siá Águeda tiravam água com um balde de cuia. Aquela água fazia esquecer a terrível expectativa de chegar um dia a apanhar um bolo de seu Proença (JURANDIR, 1998, p. 248-249).

O desânimo talvez seja a maior imagem que se pode ter da relação de Alfredo com a escola. Em plena década de 1930, a escola para o menino ainda vinha regada à palmatória e lições cansativas que só deixavam Alfredo mais abatido. 0 desalento com o sistema escolar em Chove nos campos de Cachoeira se amplia com as humilhações sofridas pelos alunos em um tempo em que nem se ouvia falar em bullying:

Uma tarde, foi nos primeiros tempos de escola, ele foi posto nu pelo Proença. Flor sorria candidamente e Proença com os seus olhos de louco e o riso canalha gritava: - Mas Flor, Flor, olha o pipi dele. O pipi, Flor! 
E Flor punha a mão na boca e seus olhos ficavam de uma cor vaga, indefinida, se enchiam de uma doce censura a pai Proença. Depois ficava séria. Era diante dos alunos. Pai Proença se excedia e então Alfredo via nos olhos já definidos de Flor uma censura azul que era para o menino qualquer coisa de humilhante, de cínico, de pior do que o riso, o olhar, os gritos de Proença (JURANDIR, 2008, p. 249).

Decerto que essa visão sobre a escola deixou raízes durante um longo período na história da educação brasileira e mesmo nos dias de hoje há quem recorde com certo saudosismo essa concepção autoritária de educação. $O$ certo é que tal período é registrado na obra de Dalcídio Jurandir como um processo educacional extremamente penoso para o educando. Alfredo representa bem esse aluno que concebe a escola como um espaço de insatisfação. Seu desagrado vem, principalmente, pelo fato de que a escola não lhe apresenta coisas que Ihe ajudem a resolver seus problemas reais:

Faltava quem o compreendesse, o animasse, o ensinasse não só a estudar como Ihe mostrar a vida. Sentia-se só, distante, imaginando sempre. Só a bolinha tomava corpo de gente, era uma amiga. Era o corpo da imaginação. Bolinha fiel e rica de sugestão! Ela sugeria tudo, ele achava desde a salvação do Brasil até uma caixa de charutos Palhaço para sua mãe (JURANDIR, 1998, p. 250).

As práticas dos castigos físicos e humilhações usadas nas escolas já eram retratadas na literatura do século XIX - o "Conto de Escola" de Machado de Assis é um bom exemplo disso. Porém, é no pensamento de Foucault que podemos vislumbrar a escola como um instrumento de controle dentro das estruturas sociais:

Não se deveria dizer que a alma é uma ilusão, ou um efeito ideológico, mas afirmar que ela existe, que tem uma realidade, que é produzida permanentemente, em tomo, na superfície, no interior do corpo pelo funcionamento de um poder que se exerce sobre os que são punidos - de uma maneira mais geral sobre os que são vigiados, treinados e corrigidos, sobre os loucos, as crianças, os escolares, os colonizados, sobre os que são fixados a um aparelho de produção e controlados durante toda a existência (FOUCAULT, 1987, p. 32-33). 
Para Foucault, a escola se equipara aos espaços das prisões no que tange seu princípio fundador. A punição tem a função de induzir as crianças a sentirem o peso do seu delito. A humilhação se constitui pela frieza da execução, por uma indiferença do executor. Os métodos disciplinares são ferramentas de minucioso controle do corpo, conduzindo os sujeitos a uma conduta dócil e utilitária. O espaço escolar é, portanto, um lugar de onde se dissemina essa estrutura de poder, exercida tanto por regras bem marcadas, quanto por sutis formas de controle: os olhares, os gestos, os símbolos etc. Enquanto a punição surge para corrigir o delito, a disciplina serve para prevenir os desvios, mantendo com isso um estado de constante vigília. Nesse caso, as escolas são antes representações morais de uma estrutura criada para exercer o poder sobre o 'outro':

Em torno de cada uma dessas "representações" morais, os escolares se comprimirão com seus professores e os adultos aprenderão que lição ensinar aos filhos. Não mais o grande ritual aterrorizante dos suplícios, mas no correr dos dias e pelas ruas esse teatro sério, com suas cenas múltiplas e persuasivas. E a memória popular reproduzirá em seus boatos o discurso austero da lei. Mas talvez fosse necessário, acima desses mil espetáculos e narrativas, colocar o sinal maior da punição para o mais terrível dos crimes: o ápice do edifício penal (FOUCAULT, 1987, p. 133).

Herdeira de uma tradição rígida, a escola passa por transformações cruciais na segunda metade do século XX e chega em suas últimas décadas prometendo profundas reformulações. O Brasil acompanhou essas mudanças e, provavelmente, o episódio mais emblemático delas seja a LDB, de 1996. No entanto, mesmo com os avanços nas concepções educacionais, a escola ainda não se tornou um lugar atraente para os educandos, pelo menos não dentro das representações literárias. Um bom exemplo disso são os contos de Maria Lúcia Medeiros.

Em "Zeus ou a menina e os óculos", tem-se a narrativa de uma menina que, sendo míope, tirava os óculos para se isolar em seu mundo imaginário de cores e formas indefinidas. A menina esperava ansiosa pelos fins de semana para ajudar no pequeno restaurante da família só para poder desfilar entras as toalhas coloridas com sua visão "privilegiada". Durante a semana aturava a escola, buscando fugas pela imaginação: "Antes disso, guardava qualquer cenário dentro da pasta escolar, junto às canetas, aos cadernos e aos papéis coloridos de 'sonho 
de valsa'. Desenhava, cantarolando, as espessas sobrancelhas da professora, debruçada na carteira da escola. Enjoava. Entediava-se" (MEDEIROS, 1994, p. 27).

Toda a descrição do ambiente escolar traduz a angústia da menina que se isolava cada vez mais em seu mundo interior:

Não acreditava no Arroio-Chuí. Não conseguia viajar pelos afluentes da margem esquerda nem atravessar depois para a margem direita. A professora era feia. A cor da saia da professora era feia. $\mathrm{O}$ giz colorido era úmido e não desenhava o cachorro de coleira e sapatos (MEDEIROS, 1994, p. 27).

Para a personagem de Medeiros, não há nada de interessante no espaço escolar, seu lugar ideal é fora daquele universo que lhe cobra conteúdos que ela não faz questão de entender. Enquanto a personagem do conto usa sua miopia para se afastar de uma realidade desinteressante, no conto "Era uma vez", a menina é uma exímia leitora. A fixação pela leitura nada tem com o ambiente escolar. Ao contrário, a escola era apenas um lugar onde a menina fazia deveres, para não ser cobrada posteriormente: "Lia com paixão e com uma incrível entrega, porque além de ser uma senhora devoradora de livros, ela fazia os deveres da escola e ninguém tinha do que se queixar" (MEDEIROS, 1994, 37). Para a pequena leitora, os livros eram mais do que simples entretenimento, como nas palavras de Celso Gutfreind:

A literatura seria para suportar um mundo sem sentido que um sujeito não sabe para o que serve, muito menos o que pretende fazer nele. O mundo o pressiona. Há de se cravar um nome no sujeito, uma função, uma etiqueta, de preferência única. O mundo pesa mais ainda sobre os ombros do adolescente (GUTFREIND, 2014, p. 20).

As duas personagens de Medeiros ilustram uma percepção nada animadora da instituição escolar. Mesmo suportando boa parte do processo educacional, as personagens enfatizam o fracasso dos modelos dominantes de escolarização. Mas em meio a toda precariedade do sistema, o que se expõe com maior ênfase são as práticas impositivas que transformam o conteúdo escolar num fim em si mesmo. 
Em "Ter, ser", o leitor entra em contato com um menino que gosta de brincar com as palavras. Nessa prosa-poética de Medeiros é possível perceber o quanto o ensino normativo vai de encontro à criatividade infantil: "Tecer. O verbo surgiu quando ele foi separar um outro que não podia conjugar: Anoitecer. (...) Duro demais era saber que o verbo não existia. Um mistério a mais, mais um, recolhido, engolido, engolfado, ruminado, abafado" (MEDEIROS, 1994, p. 43).

Mas o menino não se conformava com a imposição escolar, queria ir para além do que as regras possibilitavam. A escola era a limitação de sua ânsia por descobertas; a linguagem era um campo aberto à liberdade:

O dicionário ajudava quase sempre e aulas ele se dava e mistérios desvendava e lições aprendia, sem que fosse obrigado a ouvir a voz irritante da professora. Ele aprendia-se (sabia que estava errado) porque prendia-se (sabia que estava certo), agarrava-se ao mistério. Horas seguidas, lápis entre os dedos, jogo febril, aula inventada ao menor sopro do vento. Invento outro (pensava) é só querer, mesmo sem sopro de vento (...). Conformava-se. Jogo de beleza e de verdade. Mas beldade não era novo, já existia. E o que ele procurava era o intentado, o impossível, o indizível, incoberto (que não podia) ao invés do encoberto (que podia) (MEDEIROS, 1994, p. 43-44).

As prescrições escolares sobre a linguagem atormentavam o menino, mas as brincadeiras com as palavras o libertavam das normas. A ênfase na disciplina das regras em detrimento da inventividade linguística ainda é um dos grandes equívocos que observamos nas salas de aulas. Sobre essa realidade é que se referem os estudos de Sírio Possenti (1996), Luiz Percival Leme Britto (1997) e Marcos Bagno (1999), entre outros:

O preconceito lingüístico está ligado, em boa medida, à confusão que foi criada, no curso da história, entre língua e gramática normativa. Nossa tarefa mais urgente é desfazer essa confusão. Uma receita de bolo não é um bolo, o molde de um vestido não é um vestido, um mapa-múndi não é o mundo... Também a gramática não é a língua (BAGNO, 1999, p. 9).

Mesmo assim, a personagem de Medeiros consegue sobrepujar a rigidez das regras escolares e encontrar a poesia: "Era um menino ou era um marco? Era um 
menino atônito marcando a poesia chegando? Ou era, afinal, só um menino que se chamava Marco Antônio?" (MEDEIROS, 1994, p. 45).

$A$ aversão à escola representada pela literatura parece recriar um sentimento que envolve a maioria das crianças e jovens em idade escolar. A falta de ânimo entre os alunos é antes fruto do empobrecimento da realidade pedagógica, enfoque também das crônicas de Marcelo Coelho. Em "Elefantes", o autor começa dizendo: "Meu primeiro dia na escola foi bem ruim" (COELHO, 1995, p. 5). A crônica de Coelho fala de sua vida escolar, em especial narra o primeiro dia em que ficou com a maior vontade de fazer xixi no meio da aula. A história se desdobra com o pequeno Marcelo pedindo para ir ao banheiro e a professora, sem dar atenção, explicando coisa sobre os elefantes: "A professora continuava a falar sobre os elefantes. Assunto mais louco para um primeiro dia de aula. E a vontade de fazer xixi ia aumentando. Cruzar as pernas não adianta nessa hora" (COELHO, 1995, p. 6). No final, o menino acaba fazendo xixi na sala e com esse fato é possível tirar duas lições. A primeira apresentada pelo próprio narrador, que diz: "A coisa mais óbvia é que, quando você tem vontade de fazer xixi, vai e faz. Dane-se a professora. Coisa mais idiota é ficar pedindo para alguém deixar a gente ir ao banheiro. Banheiro é assunto meu" (COELHO, 1995, p. 8). A segunda surge ao perceber o quanto o sistema escolar não consegue enxergar as necessidades dos alunos. Não falamos apenas das necessidades fisiológicas, mas das necessidades subjetivas que abarcam seus sonhos, seus desejos e anseios. A abordagem unilateral e utilitária não é capaz de transitar pelas múltiplas subjetividades dos alunos, tão pouco de animá-los, provocá-los, envolvê-los em práticas que conjuguem a apropriação do conhecimento e a vida real, mas é possível vislumbrar nas representações literárias alguns sinais de que a escola pode ter pequenas ilhas de prazer. Na crônica que dá título ao livro, "A professora de desenho", Coelho demonstra exatamente isso:

Falando a verdade, escola é uma chatice. Pelo menos a minha era uma chatice. Essa história de aprender tabuada, fazer prova, lição de casa... eu não gostava. Ficava feliz quando aparecia uma gripe. Existe coisa melhor? Eu juntava todos os brinquedos em cima da cama. Traziam revistinhas. Chocolates. Televisão no quarto. Era ótimo.

Disse que a escola era muito chata, mas esqueci de uma coisa: as aulas de desenho. Essas eram legais (COELHO, 1995, p. 11). 
Talvez fosse capcioso perguntar a uma criança se ela preferiria ficar doente ou ir à escola, mas possivelmente a ideia do pequeno Marcelo já passou pela cabeça de muitos estudantes. Contudo, quando encontramos na escola algo ou alguém que motive e dê significado àquele espaço, aí encontramos nossa ilha de prazer:

Mas aí entrava a professora de desenho. A dona Andréia era mocinha. Tinha cabelos castanhos. Lisos e compridos.

A aula de desenho era uma farra. A gente abria os cadernos, que não tinham linhas, só folhas de papel em branco, para a gente fazer o que quisesse. Podia. Dona Andréia deixava (COELHO, 1995, p. 11).

Interessante é saber que o grande atrativo para as aulas de desenho, além da bela professora, é claro, é a liberdade para "a gente fazer o que quisesse". Parece que o caráter da "aula de desenho", estando ligado ao campo das artes, toma o sabor de livre arbítrio; mais do que isso, tem o poder de dar vazão à imaginação e à criatividade. Na falta de uma "professora de desenho", o espaço escolar torna-se um lugar a ser superado pelas incursões subjetivas das personagens, ou por subterfúgios - como a doença de Marcelo.

Ao que tudo indica, a literatura vem constantemente apontando para uma incompatibilidade no espaço escolar, que separa a busca pelo conhecimento e a satisfação dos educandos. Sem querer transformar a escola em ré, a percepção literária parece fazer uma leitura das experiências escolares pela perspectiva dos que mais sofrem as penalidades de um sistema cruel. Um sistema que perde de vista o significado da palavra conhecimento - provinda do latim e formada pela preposição co, cum (com) e pela palavra gnoscere (gênese, nascimento): etimologicamente, conhecer tem o significado de nascer-junto. Partindo desse sentido, conhecimento pode ser a experiência de descobrir ao mesmo tempo em que se nasce, aquilo que se desvenda ao nascer, ganhar vida. Neste caso, a literatura nada mais expressa do que as lacunas que existem dentro do processo educacional. As personagens aqui trabalhadas mantém uma aversão à escola, pois ela negligencia um elemento fundamental para a interação dos educandos: a articulação entre o vivido e o aprendido. Quando o conhecimento deixa de fazer sentido é porque perdeu o princípio da descoberta, aquilo que motiva e junta interno e externo numa unidade viva - coisa que se perdeu com a divi- 
são cartesiana do conhecimento. A separação ontológica entre o ser e o mundo transformou a 'descoberta' em doutrina, ou em ensino técnico.

Muitas vezes, a literatura privilegia a perspectiva do educando. Parece que, em muitos casos, a literatura sugere a ideia de Rubem Alves (2004) que nos diz que mais importante do que repassar conhecimento é motivar as crianças e tal motivação deve partir dos seus interesses. Não se pode esquecer que o princípio educacional que privilegia o interesse e a experiência do aluno se tornou evidente através do debate estabelecido pelo movimento da Escola Nova no Brasil. Contudo, para além dos pressupostos dos escolanovistas, as impressões colhidas nas obras dos autores trabalhados se reservam às representações de um olhar infantil. Dessa feita, as personagens abordadas comungam em seus refúgios internos para escapar da escola e tornar a vida mais interessante. Pedrinho e Alice aventuram-se em fantásticos países. Mas nem sempre o ponto de fuga é um lugar, pode ser outra coisa: a miopia, os livros, a bolinha (caroço de tucumã), a poesia, a professora de desenho. Se, na reflexão de Magda Soares, a apropriação da literatura pela escola é quase sempre inapropriada, o contrário (a apropriação da escola pela literatura) muitas vezes nos possibilita novos ângulos de observação do educar. Quando a literatura passa a abordar a escola, há de ser observar um desvelamento das mazelas educacionais, uma leitura franca e sincera pelo olhar das personagens infantis. 


\section{Referências}

AGUIAR, Flávio (Org.). A escola e a letra. São Paulo: Boitempo, 2009.

ALVES, Rubem. O Desejo de Ensinar e a Arte de Aprender. Campinas: Fundação EDUCAR DPaschoal, 2004.

BAGNO, Marcos. Preconceito linguístico: o que é, como se faz. São Paulo: Loyola, 1999.

BRITTO, Luiz Percival Leme. A sombra do caos: ensino de língua $\mathrm{X}$ tradição gramatical. Campinas: ALB, 1997.

COELHO, Marcelo. A professora de desenho e outras historias. São Paulo: Companhia das Letrinhas, 1995.

DOZOL, Marlene de Souza. A Escola na Literatura: do escárnio à gratidão. Revista Educação e Cultura Contemporânea. Rio de Janeiro: Universidade Estácio de Sá, v. 5, n. 9, janeiro de 2008, p. 203-214. Disponível em: http://www.estacio.br/mestrado/educacao/revista/escola lit.asp. Acesso em 15 ago. 2015.

DOZOL, Marlene de Souza. Memórias escolares: sem ressentimentos. Revista Educação e Realidade, UFRGS, 2009. Disponível em: http://seer.ufrgs.br/educacaoerealidade Larticle/viewFile/9353/5543. Acesso em 15 ago. 2015.

FOUCAULT, Michel. Vigiar e punir: nascimento da prisão. Trad. Raquel Ramalhete. Petrópolis: Vozes, 1987.

GALVÃO, Ana M. O. Amansando meninos: uma leitura do cotidiano da escola a partir da obra de José Lins do Rego (1890-1920). João Pessoa: Ed. UFPB, 1998.

GUTFREIND, Celso. A infância através do espelho: a criança no adulto, a literatura na psicanálise. Porto Alegre: Artmed, 2014.

LOBATO, Monteiro. Emília no País da Gramática. Ilustrações: Osnei e Hector Gomez. 2. ed. São Paulo: Globo, 2009.

MAZZARI, Marcus Vinícius. Representações literárias da escola. Estud. av. 1997, vol.11, n.31, p. 223-247. Disponível em: http://dx.doi.org/10.1590/S010340141997000300014. Acesso em 15 ago. 2015.

MAZZARI, Marcus Vinícius. Labirintos da aprendizagem. São Paulo: Editora 34, 2010.

MEDEIROS, Maria Lúcia. Zeus ou a menina e os óculos. 2. ed. Belém: Maria Lúcia Medeiros, 1994.

POSSENTI, Sírio. Por que (não) ensinar gramática na escola. Campinas: Mercado de Letras/Associação de Leitura do Brasil, 1996.

SOARES, Magda. A escolarização da literatura infantil e juvenil. In EVANGELISTA, Aracy et. al. (Orgs.). Escolarização da leitura literária: o jogo do livro infantil e juvenil. Belo Horizonte: Autêntica, 1999. 